\title{
BMJ Open Communication skills training for the radiotherapy team to manage cancer patients' emotional concerns: a systematic review
}

\author{
Mara Myrthe van Beusekom, ${ }^{\oplus 1}$ Josie Cameron, ${ }^{2}$ Carolyn Bedi, ${ }^{2}$ Elspeth Banks, ${ }^{3}$ \\ Gerald Humphris ${ }^{1}$
}

To cite: van Beusekom MM, Cameron J, Bedi C, et al. Communication skills training for the radiotherapy team to manage cancer patients' emotional concerns: a systematic review. BMJ Open 2019;9:e025420. doi:10.1136/ bmjopen-2018-025420

- Prepublication history and additional material for this paper are available online. To view these files, please visit the journal online (http://dx.doi org/10.1136/bmjopen-2018025420).

Received 13 July 2018 Revised 20 February 2019 Accepted 21 February 2019

A) Check for updates

(c) Author(s) (or their employer(s)) 2019. Re-use permitted under CC BY-NC. No commercial re-use. See rights and permissions. Published by BMJ.

${ }^{1}$ School of Medicine, University of St Andrews, St Andrews, UK ${ }^{2}$ Edinburgh Cancer Centre, Western General Hospital,

Edinburgh, UK

${ }^{3}$ Patient Representative, National Cancer Research Institute, London, UK

Correspondence to Dr Mara Myrthe van Beusekom; mvb4@st-andrews.ac.uk

\section{ABSTRACT}

Objectives Many cancer patients experience high levels of anxiety and concern during radiotherapy, often with long-lasting effects on their well-being. This systematic review aims to describe and determine the effectiveness of communication skills training (CST) for the radiotherapy team (RT) to improve conversations in this setting and to support patients with emotional concerns.

Design Systematic review.

Interventions CST for RT members.

Data sources On 17 April 2018, databases Medline, Embase, Scopus and PsycNET were searched.

Eligibility criteria, Population, Intervention, Comparison, Outcome(PICO) Quantitative and/or qualitative articles were included that evaluate the effect of a CST for RT members (vs no CST) on communication behaviours and patients' emotional concerns.

Data extraction and synthesis Articles were appraised using the mixed-methods appraisal tool, and a narrative synthesis was performed.

Results Of the nine included articles, five were randomised controlled trials, three were mixed-methods and one used repeated measurements. Four of the five different CST programmes managed to increase emotional communicative behaviour from the RT, and all studies measuring patient communicative behaviour found an improvement in at least one of the hypothesised outcomes. Two studies examining patient anxiety and concerns found a positive effect of the CST, although one found a negative effect; two other studies without a positive effect on mood made use of both empathic CST and tools.

Conclusions There are promising indications that CST can be successfully introduced to improve emotional conversations between RT members and patients. With the right support, the RT can play an important role to help patients cope with their emotional concerns. Future work is necessary to confirm initial promising results and to ensure the learnt communication skills are sustained.

\section{INTRODUCTION}

Many cancer patients who undergo radiotherapy treatment experience concerns about the quality of their daily life, ${ }^{1}$ are anxious or worried, or feel uncertain about their future. ${ }^{2}$
Strengths and limitations of this study

- A systematic search was carried out in four comprehensive databases (ie, Medline, Embase, Scopus and PsycNET) and reference lists were snowballed.

- Inclusion of both quantitative and qualitative findings benefits the review.

- A tool specifically developed for mixed-methods studies (ie, the mixed-methods appraisal tool) was used to evaluate included articles.

- Findings are limited by the small number of quantitative studies published in this area.

- Despite limited numbers (peer-reviewed, Englishlanguage only), good-quality studies allow for careful insights into the effectiveness of communication skills training in the radiotherapy setting and indicate future directions.

Patients' anxiety is particularly high just prior to treatment, during the radiotherapy simulation session. ${ }^{3}$ At the start of their therapy, patients may fear 'the unknown' and can be afraid of side effects, such as severe skin reactions, damage to organs and being tired. ${ }^{4}$ During and after radiotherapy treatment, the most common concern that cancer patients and survivors experience is that of cancer recurrence, ${ }^{5}$ that is, "the fear, worry, or concern relating to the possibility that cancer will come back or progress'. ${ }^{6}$ Such concerns can have long-lasting effects on patients' quality of life and well-being. ${ }^{7}$

Communication during radiotherapy treatment could play an important role to address patients' concerns: a recent study from our group found that patients whose fear of cancer recurrence trajectories decrease during radiotherapy express more cues and concerns during appointments with their therapeutic radiographers and refer to cancer more directly. ${ }^{8}$ In addition, the moments when patients' anxiety levels are highest at 
the start of radiotherapy correspond to a peak in information needs. ${ }^{9}$ During radiotherapy, patients have 'on treatment review' by therapeutic radiographers ${ }^{10}$ in the UK, and these consultations might be an ideal opportunity to provide psychosocial support. Indeed, a recent review shows that increased communication and information sharing can benefit both patients and radiation therapists. ${ }^{11}$

However, not all forms of support are equally effective, and it has been suggested to develop communication skills training (CST) for the radiotherapy team (RT) to improve communication-related and patient outcomes. ${ }^{12}{ }^{13}$ Also radiation therapists themselves indicate that they would appreciate further education to help patients deal with emotional distress. ${ }^{14}$ Various CST courses for oncology professionals in general have already shown improvements in clinicians' self-efficacy, communication skills and strategies, as well as transfer of these strategies into the clinical practice. ${ }^{15} 16$ CST programmes seem particularly effective at encouraging healthcare professionals (HCPs) to increase their use of open questions and show empathy towards patients. ${ }^{17}$

Unfortunately, even though managing patients' emotions, triggered by their condition and treatment, is the role of all health service staff, including the RT team, little attention has been given to the effectiveness of CST to improve communication with patients in the setting of radiation therapy. Furthermore, a specific question remains as to whether patients' communication with the RT also leads to improvements for patients to manage their emotional concerns. The aim of this systematic review is therefore to provide an overview of the available evidence on whether CST can help RT members to support cancer patients in managing their distress during treatment. The review will describe and determine the effectiveness of CST to improve communication behaviours and support patients' emotional concerns.

\section{MATERIALS AND METHODS \\ Search strategy}

On 17 April 2018, databases Ovid MEDLINE, Scopus, PsycNET and Ovid Embase were searched for a combination of the keywords (radiation therapist*, radiotherapist*, radiographer*, technologist*, radiotherapy team or radiation oncologist*) and (train*, educat*, workshop, module, teach, curricul* or learn) and (cancer, carcinoma or neoplasm) and (distress, fear*, worry, worries, concern*, anxiety or emotion*) and patient*, without restriction on publication date. For a tailored search per database, see online supplementary material figure S1. Snowballing was used to search the reference lists of included articles.

\section{Selection criteria}

Duplicates were removed. Titles and abstracts were screened for full-text evaluation (MMvB). When there was uncertainty about the suitability of an article for inclusion in the analysis, authors MMvB and GH reached consensus on the inclusion through discussion. To be included, studies had to be published in a peer-reviewed journal, written in English, and describe and evaluate a CST programme for members of the RT to address patients' concerns, worries or anxiety during radiotherapy treatment. When various healthcare professions were involved in a training programme, at least $50 \%$ of the sample had to be specialised in radiotherapy for the article to be included.

\section{Data extraction and analysis}

The following data were extracted from the included articles into a table: study type, number and characteristics of the patient sample, number of the radiotherapy staff sample, the CST intervention (duration, content, didactic and experiential methods), moment of delivery of new skills to the patient, moment of outcome measurement, methods to measure outcomes, RT and patient communicative behaviour (no limits; includes observed and self-reported) and all outcomes relating to patients' emotions, which included levels of concerns, worries or anxiety.

Articles were assessed for quality using the mixedmethods appraisal tool (MMAT) ${ }^{18}$ which has promising reliability and was specifically designed to enable the appraisal of qualitative, quantitative and mixed-methods studies, making it ideally suited for mixed-studies reviews. The MMAT offers sets of questions relevant for different study types: that is, qualitative studies, quantitative randomised controlled trials (RCTs), quantitative non-randomised studies and quantitative descriptive studies. For mixed-methods papers, the qualitative section is combined with the relevant quantitative section, and three additional questions are answered to assess the mixed-methods aspect of the study.

Based on the limited number of studies that could be included, it was decided to conduct a narrative synthesis rather than a meta-analysis. This approach was considered more appropriate considering the limited number of studies that examined similar outcomes, and the variation in content between the different training programmes (ie, heterogeneity).

\section{Patient and public involvement}

A patient representative/advocate was involved in the preparation of the systematic review and is included in the author byline.

\section{RESULTS}

\section{Description of studies}

The systematic search resulted in 378 articles (MEDLINE 95, Scopus 151, PsycNET 20, Embase 112), of which 177 were unique and screened for eligibility (figure 1, Preferred Reporting Items for Systematic Reviews and Meta-Analyses flowchart ${ }^{19}$ ). Based on the titles and abstracts, 23 references were included for full-text evaluation. Nine articles from the search were included (table 1); 


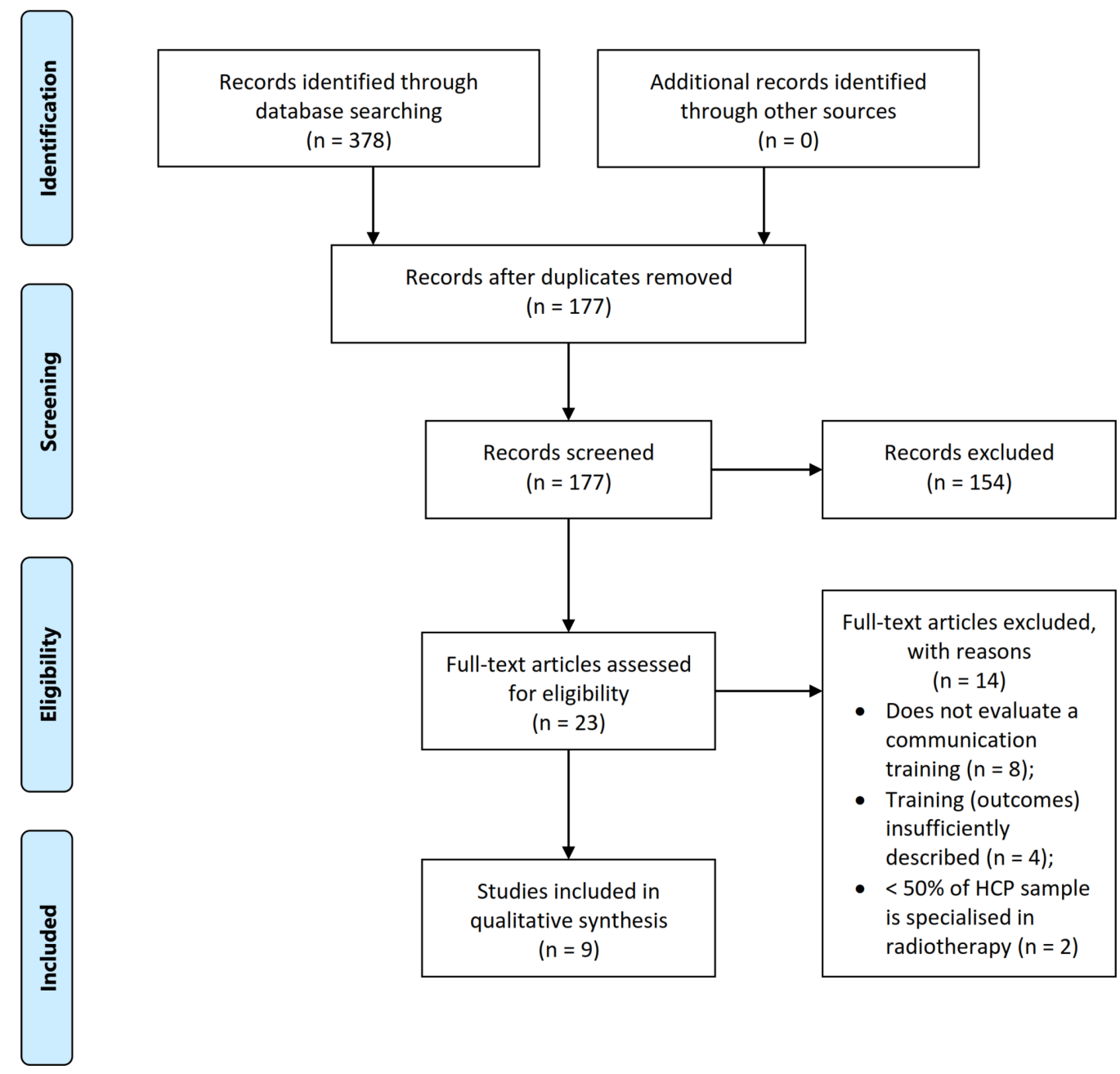

Figure 1 Preferred Reporting Items for Systematic Reviews and Meta-Analyses flowchart for the systematic review. HCP, healthcare professional.

snowballing reference lists did not result in the inclusion of additional articles. Five articles described RCTs, three articles made use of mixed methods and another article used repeated measurements. All studies scored $50 \%$ or higher on quality using the MMAT (online supplementary table S1). However, some articles described pilot studies, ${ }^{20-22}$ with relatively small numbers of participants. In addition, randomisation is not always described in detail ${ }^{23-25}$ and inclusion of HCPs is usually on voluntary basis, with moderate inclusion rates, forming a risk for selection bias of more motivated members of the RT in the intervention groups. When qualitative/mixed-methods are used, little consideration is given to the influence on the setting and researcher on outcomes or to the limitations of the integration of the various methods. ${ }^{2022} 26$ In addition, limited descriptions of theoretical models behind the developed interventions are given, which makes it difficult to link the topics and learning strategies that are used in the training programmes to HCP and patient outcomes.

\section{Sample characteristics}

Four articles included radiation therapists in the training programme, ${ }^{20-22} 26$ three included various members of the RT, including secretaries, nurses, physicians and physicists, ${ }^{23-25}$ one article included nurses and radiographers ${ }^{27}$ and another targeted radiation oncologists. ${ }^{28}$ The number of staff included ranged between $n=4{ }^{20}$ and $n=465 .{ }^{25}$ In most studies, ${ }^{20} 21$ 23-26 effects of the training intervention for staff were evaluated looking at communication with breast cancer patients. The number of patient participants included in the articles ranged between $n=12^{20}$ and $\mathrm{n}=313{ }^{25}$ Two articles included patients with a variety of cancer types, including breast, urological, gynaecological, head and neck, brain and lung cancer. ${ }^{27} 28$ Only one study made use of a simulated patient to evaluate communicative behaviour of HCPs. ${ }^{23}$ Patients' mean age was consistently around 55-60 for the various studies.

\section{Training programme}

The nine articles described five different training programmes, of which three focused only on (non) verbal communication skills, while the other two also introduced the RT to the use of tools (ie, mindfulness strategies ${ }^{22}$ and the distress thermometer and problem list [DT\&PL] $)^{27}$ to support emotional conversations with patients. Training periods varied from a single training session, ${ }^{27} 28$ to two 


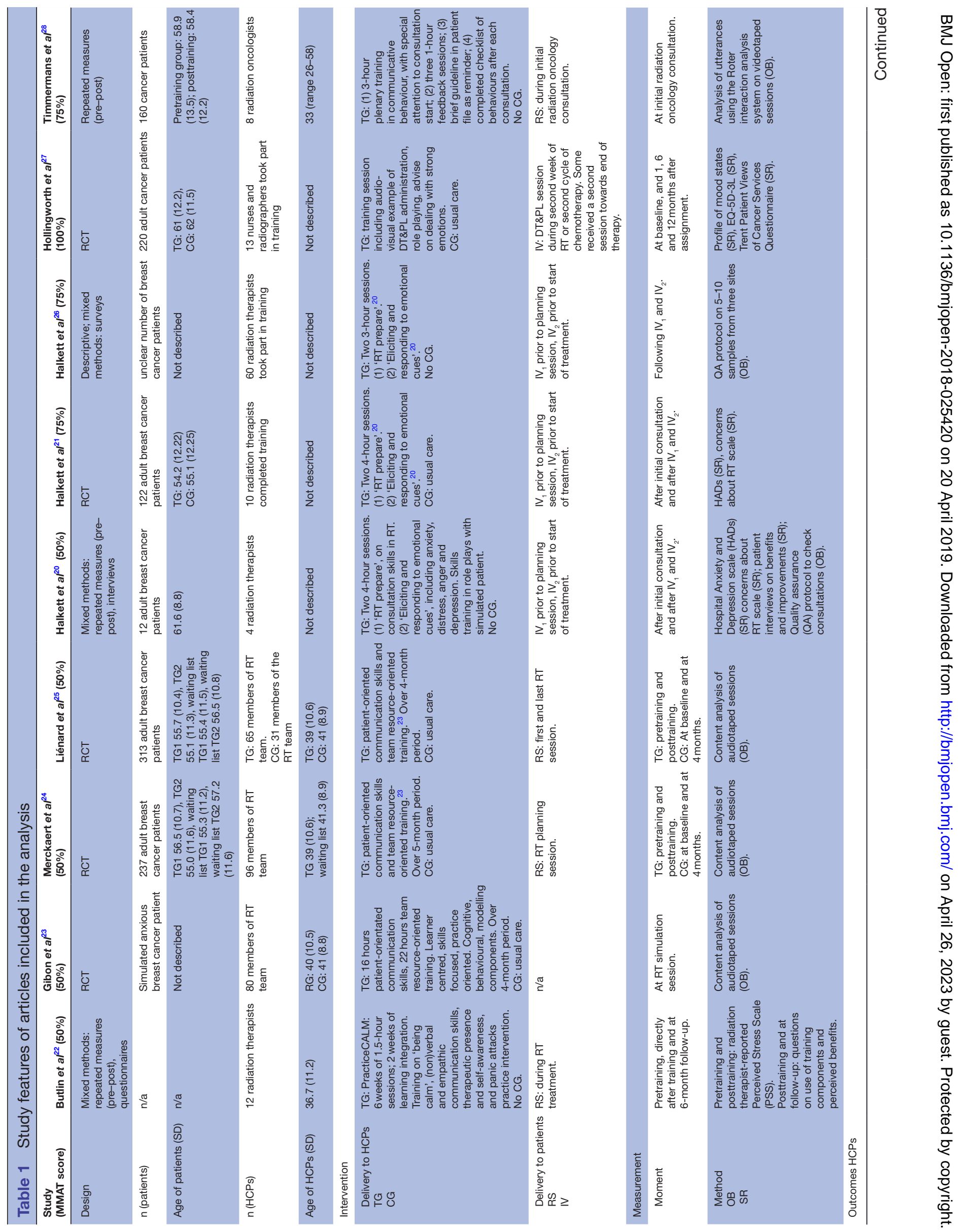



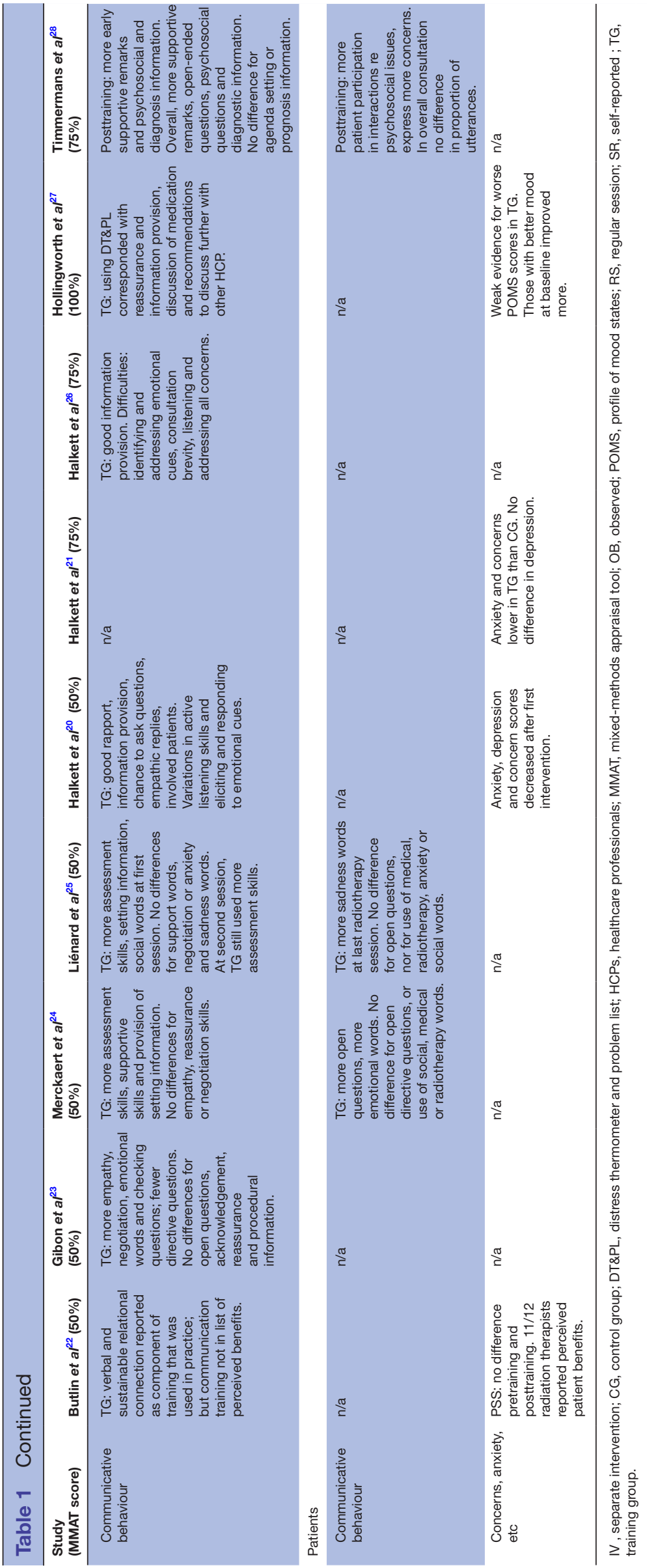
3-hour or 4-hour sessions, ${ }^{20} 2126$ weekly sessions over a period of 8 weeks $^{22}$ and a 38-hour training programme over a period of 4-5 months. ${ }^{23-25}$

While all training programmes addressed emotional communication with cancer patients undergoing radiotherapy, specific objectives and topics covered varied between the programmes. The PracticeCALM project aimed to support the RT with strategies to reduce patient anxiety and covered a session on stress, communication and being calm, therapeutic presence and self-awareness, PracticeCALM interventions and management of panic attacks. ${ }^{22}$ Another project wanted to improve RT members' assessment of patients' concerns and needs, information provision and communication about resources within the team and communication between colleagues. $^{23-25}$

The studies by Halkett and colleagues aimed to train the RT in information provision about radiotherapy, based on Pendleton's model for consultations, ${ }^{29}$ with a focus on support rapport-building, awareness of the patient's emotional status and additional needs, setting a mutually agreed agenda, building partnership and making appropriate use of time and resources. Furthermore, another objective was to help the RT recognise and respond to patients' emotions ${ }^{202126}$. The objective of the project in the use of the DT\&PL was to facilitate the discussion of patients' concerns. The training introduced the visual tool and supported RT members with how to deal with strong emotions. ${ }^{27}$

The final training package aimed to increase patient participation in the consultation. This programme covered agenda setting, investigating the patient's medical and psychosocial status, exploring the patient's ideas, reacting supportively, asking open questions, information provision about diagnosis, prognosis, treatment intent and emotional impact, and discussing the treatment decision and informed consent. In addition, the focus of the training was to discuss the first three topics at the very start of the consultation. ${ }^{28}$

All training programmes made use of role play in the training programme, of which four utilised simulated patients. ${ }^{20} 212628$ Other didactic methods included reflection, ${ }^{22}$ individual feedback on consultations ${ }^{22} 28$ and skill exercises. ${ }^{23-25}$ Halkett and colleagues saw that some of the positive effects of their intervention were short lasting. ${ }^{21}$ Strategies used to promote the transfer of communication skills into the clinical setting included holding a follow-up 'consolidation workshop',25 or for members of the RT to regularly perform self-analysis of consultations. ${ }^{26}$ Having trainers provide feedback on posttraining consultations $^{20} 28$ appeared to be particularly helpful.

Most studies described the facilitators of the workshops as 'experienced' or 'trained', ${ }^{20} 2123-2628$ and two also gave the background of the facilitators. The first study included a communication skills facilitator with a medical background ${ }^{20}$ and one with a background in clinical psychology and communication skills. The second programme benefited from a facilitator with a background in radiation therapy. ${ }^{26}$ Two studies did not describe the background or expertise of the workshop facilitators. ${ }^{22} 27$

\section{Delivery to patients}

The majority of the newly acquired communication skills from the members of the RT were applied to standard care sessions with patients, ${ }^{22} 242528$ including the initial consultation with the radiation oncologist, ${ }^{28}$ the radiotherapy planning session, ${ }^{24}$ throughout radiotherapy treatment ${ }^{22}$ or during the first and last radiotherapy session..$^{25}$ On the other hand, communication skills acquired in the 'RT prepare' and 'eliciting and responding to emotional cues' programmes $^{202126}$ were delivered in a separate session with the patient, one prior to the radiotherapy planning session and a second session prior to the start of treatment. Also, the training from the DT\&PL workshop ${ }^{27}$ was applied in a separate intervention with patients during the second week of radiotherapy treatment, and if it was deemed necessary, in a second session towards the end of the patient's therapy.

\section{Outcome measures}

This review focused on outcomes regarding communicative behaviour of members of the RT and patients, and measures of anxiety or concerns from patients. Three studies performed a content analysis on audiotaped sessions, ${ }^{23-25}$ the Halkett articles made use of the widely used Hospital Anxiety and Depression scale (HADs), ${ }^{30}$ and two measures developed by the authors: a concerns about radiotherapy scale, and a quality assurance protocol to analyse audiotaped consultations. ${ }^{20} 2126$ Timmermans and colleagues used the Roter interaction analysis system, a method to code medical dialogue, ${ }^{31}$ on videotaped consultations. ${ }^{28}$ The two studies that found no or possibly negative effects from the skills training in their quantitative data ${ }^{22}$ used profile of mood states (POMS), which evaluates six mood states ${ }^{32}$ and a radiation therapist-reported Perceived Stress Scale (PSS), which measures perception of stress ${ }^{33}$

\section{Effects on RT communicative behaviour}

Studies that described communicative behaviour from RT members after training without comparing to a control group found good results for rapport, ${ }^{20}$ information provision, ${ }^{202627}$ opportunity to ask questions, ${ }^{20}$ empathic replies $^{20}$ and reassurance. ${ }^{27}$ Two of these studies, of which one an RCT, indicated that variations were found in the extent to which RT members could identify and respond to emotional cues and concerns. ${ }^{20}{ }^{26}$ Also studies that compared communicative behaviour pretraining and posttraining or between a training and control group found varying results. An overview of effects of CST for studies that conducted an RCT is given in table 2. Most communication training packages were successful at increasing several aspects of RT's communicative behaviour, but at the same time there were several instances where hypothesised effects were not detected. Specifically, two studies 
Table 2 Effects of CST on communicative behaviours and patient concerns for studies that conducted an RCT

\begin{tabular}{|c|c|c|}
\hline Effect of CST (RCTs) & Negative & None \\
\hline \multicolumn{3}{|l|}{$\begin{array}{l}\text { On RT communicative } \\
\text { behaviour }\end{array}$} \\
\hline Gibon et $a l^{23}$ & & $\begin{array}{l}\text { Open Qs: RR } 1.06 ; 95 \% \mathrm{Cl} 0.47 \text { to } 2.40 ; p=0.889 \\
\text { Acknowledgement: RR } 0.87 ; 95 \% \mathrm{Cl} 0.68 \text { to } 1.11 \text {; } \\
\mathrm{p}=0.252 \\
\text { Reassurance: RR } 0.76 ; 95 \% \mathrm{Cl} 0.45 \text { to } 1.28 ; \\
p=0.305 \\
\text { Procedural information: } \mathrm{RR} 1.01 ; 95 \% \mathrm{Cl} 0.84 \text { to } \\
122 ; p=0.879\end{array}$ \\
\hline
\end{tabular}

\section{Positive}

\begin{tabular}{|c|c|}
\hline Merckaert et al ${ }^{24}$ & $\begin{array}{l}\text { Empathy: RR } 1.98 ; 95 \% \mathrm{Cl} 0.10 \text { to } 39.25 ; p=0.654 \\
\text { Reassurance: } \mathrm{RR} 0.93 ; 95 \% \mathrm{Cl} 0.58 \text { to } 1.50 ; \\
p=0.772 \\
\text { Negotiation: } \mathrm{RR} 1.00 ; 95 \% \mathrm{Cl} 0.25 \text { to } 4.06 ; p=0.999\end{array}$ \\
\hline Liénard et $a l^{25}$ & 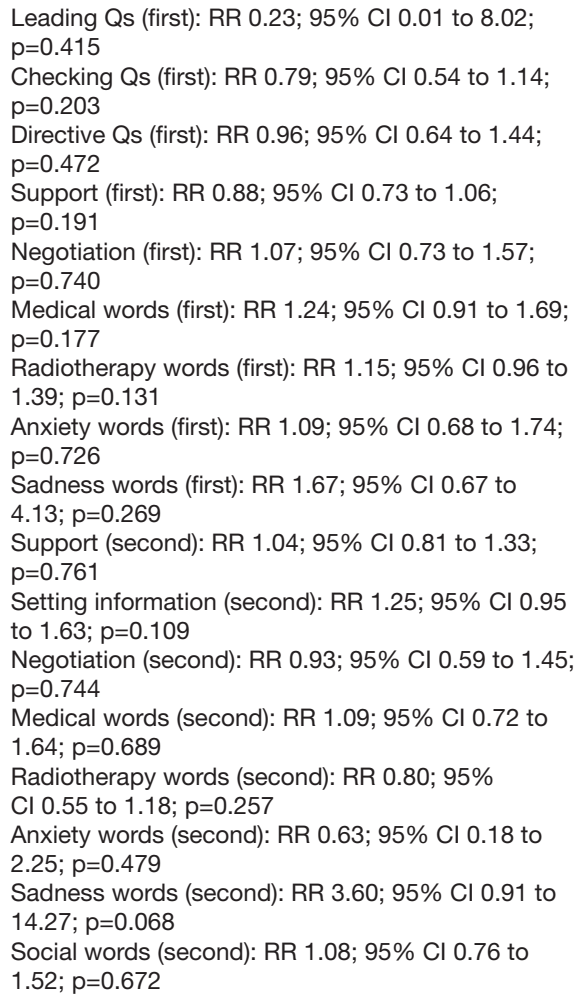 \\
\hline
\end{tabular}

\begin{tabular}{|c|c|c|}
\hline \multicolumn{3}{|l|}{$\begin{array}{l}\text { On patient communicative } \\
\text { behaviour }\end{array}$} \\
\hline Merckaert et al ${ }^{24}$ & $\begin{array}{l}\text { Open directive questions: } \mathrm{RR} 1.01 ; 95 \% \mathrm{Cl} 0.50 \text { to } \\
\text { 4.03; } p=0.519 \\
\text { Social words: } \mathrm{RR} 1.03 ; 95 \% \mathrm{Cl} 0.80 \text { to } 1.32 ; \\
p=0.838 \\
\text { Medical words: RR } 0.88 ; 95 \% \mathrm{Cl} 0.63 \text { to } 1.22 ; \\
p=0.434 \\
\text { Radiotherapy words: } \mathrm{RR} 1.02 ; 95 \% \mathrm{Cl} 0.79 \text { to } 1.31 \text {; } \\
p=0.898\end{array}$ & $\begin{array}{l}\text { Open questions: RR } 3.41 ; 95 \% \mathrm{Cl} 1.19 \text { to } 9.76 \text {; } \\
p=0.022 \\
\text { Emotional words: RR } 1.67 ; 95 \% \mathrm{Cl} 1.07 \text { to } 2.60 \text {; } \\
p=0.025\end{array}$ \\
\hline
\end{tabular}

Continued 


\begin{tabular}{|c|c|c|c|}
\hline Effect of CST (RCTs) & Negative & None & Positive \\
\hline Liénard et $\left.a\right|^{25}$ & & 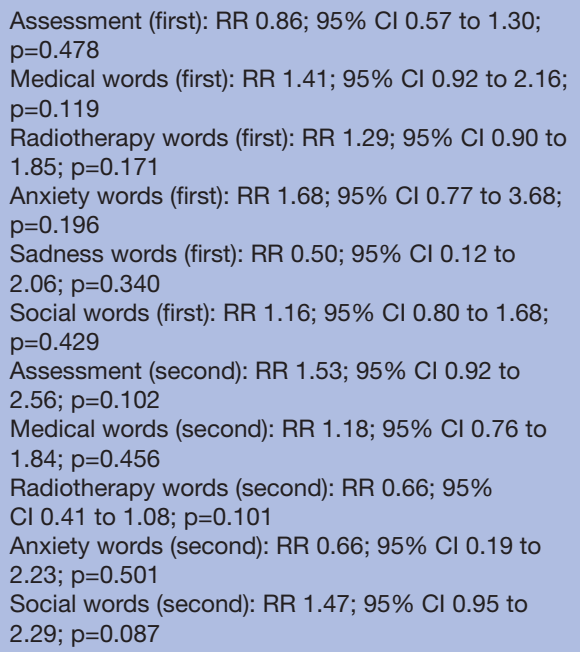 & $\begin{array}{l}\text { Sadness words (second): RR } 5.86 ; 95 \% \text { Cl } 1.28 \text { to } \\
26.81 ; p=0.023\end{array}$ \\
\hline \multicolumn{4}{|c|}{ On patient concerns, anxiety } \\
\hline Halkett et $a l^{21}$ & & $\begin{array}{l}\text { Depression (T2): } b-0.068 ; S E 0.052 ; p=0.194 \\
\text { Anxiety (T3): } b-0.033 ; \text { SE } 0.080 ; p=0.683 \\
\text { Depression (T3): b -0.085; SE 0.061; } p=0.162 \\
\text { RT concerns (T3): b -0.048; SE 0.232; } p=0.835\end{array}$ & $\begin{array}{l}\text { Anxiety (T2): } b-0.145 ; \text { SE 0.056; } p=0.009 \\
\text { RT concerns (T2): } b-0.918 ; \text { SE 0.234; } p<0.001\end{array}$ \\
\hline Hollingworth et $a l^{27}$ & $\begin{array}{l}\text { Total POMS: }-5.16 \\
95 \% \mathrm{Cl}-10.36-0.04 \\
\mathrm{p}=0.52\end{array}$ & & \\
\hline
\end{tabular}

Effects on patient communicative behaviour.

CST, communication skills training; POMS, profile of mood states; Qs, questions; RCTs, randomised controlled trials; RR, Relative Rate.

(RCT and repeated measurement) found an increase in supportive skills of RT members in the intervention group $^{24} 28$; another RCT did not detect an effect for this outcome. ${ }^{25}$ A positive effect of CST was detected on RT members' use of emotional ${ }^{23}$ and social words, ${ }^{25}$ but not on anxiety and sadness words. ${ }^{25}$ One high-quality repeated measurement study found an increase in the use of open-ended questions, ${ }^{28}$ but an RCT project detected no difference for the number of open questions asked. ${ }^{23}$ The latter study did, however, find an increase in empathic communication skills, ${ }^{23}$ while another RCT did not detect the hypothesised effect on empathy. ${ }^{24}$ No difference was detected for reassurance provision in two RCTs within the same project, ${ }^{23}{ }^{24}$ but a third RCT using another CST package did see that RT members provided more reassurance after training ${ }^{27}$ and another study found that RT members responded more to questions about psychosocial aspects. ${ }^{28}$ Increased assessment skills and use of social words were retained at a follow-up session 4 months after training. ${ }^{25}$

Most studies also evaluated the effect of the CST on patient outcomes. ${ }^{20-22} 24252728$ With respect to communicative behaviour, it was seen that the newly acquired skills from the members of the RT lead to patients asking more open questions, ${ }^{24}$ although the follow-up RCT of this project could not detect a difference for this outcome. ${ }^{25}$ Varying results were seen for patients' use of emotional words: three (RCT and repeated measurement) studies found an increase in the use of emotional ${ }^{24}$ and sadness words ${ }^{25}$ and found that patients expressed their concerns more frequently. ${ }^{28}$ However, in two RCTs, no difference could be detected for the number of social, ${ }^{24}{ }^{25}$ anxiety or sadness $\operatorname{words}^{25}$ posttraining. Timmermans and colleagues saw that their CST led to patients participating more in conversations regarding psychosocial issues. ${ }^{28}$

\section{Effects on patient concerns}

In addition, three papers examined effects of communication training on patients' levels of anxiety and other concerns. It was seen that levels of anxiety, ${ }^{20}{ }^{21}$ depression $^{20}$ (HADs) and concern scores decreased after the intervention, ${ }^{20} 21$ although a pilot RCT that hypothesised to lower depression levels did not find an effect on this outcome. ${ }^{21}$ Butlin and colleagues found no quantitative effect on patient stress levels as perceived by radiation therapists (PSS), but qualitatively, patient benefits were reported. ${ }^{22}$ Hollingworth and colleagues on the other hand found weak evidence for worse mood states (POMS) for patients in the intervention group. ${ }^{27}$

\section{DISCUSSION}

To our knowledge, this is the first review to have looked at the effectiveness of communication skills programmes for members of the RT to support cancer patients with their emotional concerns during treatment. Despite the available evidence on the importance of the relationship between patients and the $\mathrm{RT}^{34-36}$ and recommendations 
to target staff education to increase comfort levels with emotional conversations, ${ }^{14}{ }^{37}$ only nine articles met the review's inclusion criteria, of which seven focused specifically on communication skills. Surprisingly, even though fear of cancer recurrence is the most common concern for patients during and after radiotherapy treatment, ${ }^{5}$ none of the included studies took this specific concern into consideration; instead, the current focus is on patient anxiety, (general) concerns and depression. While success was not always consistently obtained for the various training programmes, there was indeed evidence for the potential of CST to improve communicative behaviour of members of the RT and patients as well as patient outcomes. CST appeared to be particularly effective at increasing supportive skills of RT members ${ }^{24} 28$ and the use of emotional words by both staff and patients. ${ }^{23}{ }^{24}$ These findings correspond with earlier evidence on effects of CST on HCPs who work with cancer patients. ${ }^{17}$ Moreover, there was promising evidence ${ }^{38}$ that training programmes for radiation therapists targeted at interactions prior to the radiotherapy planning session and start of treatment could successfully reduce patient levels of anxiety and concerns. ${ }^{21}$

A limitation of this review is that as a result of the restricted number of articles that describe CST in the setting of radiotherapy sessions and the heterogeneity of content and outcome measures of the different programmes, a quantitative meta-analysis was not considered appropriate. As a qualitative synthesis is more easily influenced by personal bias, results were discussed between the authors. In addition, it is possible that the systematic search has missed articles; however, snowballing the reference lists of articles that were found in the search did not result in the addition of new relevant articles. Other limitations of the review include that only English-language papers were included, one author screened for titles/abstracts, there was no prospective protocol registration, and that only peer-reviewed literature (ie, no grey literature) was included.

While the evidence suggests that CST for members of the RT is an area worth continued exploration, there are several barriers that need to be overcome in the implementation of such CST programmes. According to the 'Capability', 'Opportunity', 'Motivation' and 'Behaviour' (COM-B) system that describes factors that influence people's behaviour, in addition to RT members having the necessary capabilities, that is, knowledge and skills on how to manage emotional conversations with patients, their behaviour will be influenced by their motivation and the opportunities available to them to make these conversations possible or prompt them. ${ }^{39}$

The CST, therefore, needs to be adjusted to the time schedule of the RT and can only become a success with full support from the organisation and motivated participants. ${ }^{23}$ In addition, in practice, it can be difficult to find the time and a quiet space to hold the sometimes slightly more elaborate conversations with patients. ${ }^{202627}$ These logistical considerations, such as asking the patient to arrive a few minutes early or having a free space available, need to be addressed in the design of a CST package in order for it be successfully implemented in the setting of radiotherapy treatment. This issue is particularly important since there is evidence that time is one of the main factors that influences skill levels of radiation therapists to manage emotional interactions with patients. ${ }^{40}$

With respect to RT members' knowledge and skills to facilitate emotional conversations and help patients manage their concerns, consolidation is another important area to address. Role play is commonly used and encouraged by workshop participants, ${ }^{26}$ also in the context of CST for medical imaging students. ${ }^{41}$ The finding that having trainers provide feedback on posttraining consultations ${ }^{2028}$ is particularly helpful is strongly advocated by Heaven and colleagues' model for clinical supervision. ${ }^{42}$ This supportive activity can be enhanced in combination with behaviour prompts in the form of reminders in patients' medical files. This joint strategy appears to trigger a wide range of positive communication behaviours. ${ }^{28}$

Longer workshops to consolidate skills are deemed unfeasible to implement on a national level ${ }^{26}$ due to the previously addressed time constraints, but recent work has shown promising results with single-day training. ${ }^{43}$ As recommended in several of the included studies, ${ }^{21}{ }^{23}$ it is advisable to perform a cost-benefit analysis for future interventions. The two studies included in this review that make use of communication skills workshops, but as part of an intervention that uses a tool of some sorts both have less positive (or even negative) outcomes compared with the other interventions that focus on communication only. ${ }^{22} 27$ This could suggest that when it comes to outcomes regarding emotional communication and patient concerns, it might be a better investment of resources to fully focus training for RT members on empathic communication skills.

\section{CONCLUSIONS}

In conclusion, CST is a promising strategy to increase the opportunity for empathic communication between members of the RT and patients, although little is known about how to obtain these positive results consistently or how to retain skills over a longer period. There is limited but high level evidence that the RT members' communication skills can also successfully be transferred to the clinical practice to reduce patient levels of anxiety and concerns.

However, research in this context is still in its infancy and more work is needed to understand which components of CST programmes actually lead to positive outcomes for members of the RT and patients, so that these outcomes can be obtained consistently. In addition, with fear of cancer recurrence being the most common concern that patients who undergo radiotherapy experience, it would be worth investigating whether CST can help RT members to support patients with this particular 
concern. More research is also needed to explore how to consolidate (better) the learnt communication skills and, if this leads to longer or multiple training sessions, weigh the cost and benefits of the implementation of such workshops at multiple sites. To encourage motivated participation by members of the RT, service design or codesign strategies can be explored to involve staff as partners in the design of CST, so that their needs and preferences are incorporated in the fundaments of the training package.

Contributors GH and MMvB set up the search, included articles and extracted and analysed data. MMvB drafted the first version of the paper. JC, CB, EB and $\mathrm{GH}$ advised on interpretation of data and revised the draft. MMvB finalised the manuscript, which was approved by all authors.

Funding This work was supported by Breast Cancer Now, grant number 2017MayPR898.

Competing interests None declared.

Patient consent for publication Not required.

Provenance and peer review Not commissioned; externally peer reviewed.

Data sharing statement All key data are provided in the paper. Additional details can be provided on request by the corresponding author.

Open access This is an open access article distributed in accordance with the Creative Commons Attribution Non Commercial (CC BY-NC 4.0) license, which permits others to distribute, remix, adapt, build upon this work non-commercially, and license their derivative works on different terms, provided the original work is properly cited, appropriate credit is given, any changes made indicated, and the use is non-commercial. See: http://creativecommons.org/licenses/by-nc/4.0/.

\section{REFERENCES}

1. Hollant L, Single MP, Gaines K, et al. Assessing distress in patients with gastrointestinal tumors during radiotherapy. Journal of Clinical Oncology 2016;34:e18087.

2. Sundaresan P, Sullivan L, Pendlebury S, et al. Patients' perceptions of health-related quality of life during and after adjuvant radiotherapy for T1N0M0 breast cancer. Clin Oncol 2015;27:9-15.

3. Lewis F, Merckaert I, Liénard A, et al. Anxiety and its time courses during radiotherapy for non-metastatic breast cancer: a longitudinal study. Radiother Oncol 2014;111:276-80.

4. Halkett GK, Kristjanson LJ, Lobb EA. 'If we get too close to your bones they'll go brittle': women's initial fears about radiotherapy for early breast cancer. Psychooncology 2008;17:877-84.

5. Simard S, Thewes B, Humphris G, et al. Fear of cancer recurrence in adult cancer survivors: a systematic review of quantitative studies. $J$ Cancer Surviv 2013;7:300-22.

6. Lebel S, Ozakinci G, Humphris G, et al. From normal response to clinical problem: definition and clinical features of fear of cancer recurrence. Support Care Cancer 2016;24:3265-8.

7. Koch L, Bertram H, Eberle A, et al. Fear of recurrence in longterm breast cancer survivors-still an issue. results on prevalence, determinants, and the association with quality of life and depression from the cancer survivorship-a multi-regional population-based study. Psychooncology 2014;23:547-54.

8. Barracliffe L, Yang Y, Cameron J, et al. Does emotional talk vary with fears of cancer recurrence trajectory? A content analysis of interactions between women with breast cancer and their therapeutic radiographers. J Psychosom Res 2018;106:41-8.

9. Halkett GK, Kristjanson LJ, Lobb E, et al. Meeting breast cancer patients' information needs during radiotherapy: what can we do to improve the information and support that is currently provided? Eur $J$ Cancer Care 2010;19:538-47.

10. Cameron JL, Blyth CM, Kirby AS. An audit of a radiotherapy review clinic for breast cancer patients: a multi-disciplinary approach. $J$ Radiother Pract 2008;7:233-9.

11. Elsner K, Naehrig D, Halkett GKB, et al. Reduced patient anxiety as a result of radiation therapist-led psychosocial support: a systematic review. J Med Radiat Sci 2017;64:220-31.

12. Mitchell AJ, Lord K, Slattery J, et al. How feasible is implementation of distress screening by cancer clinicians in routine clinical care? Cancer 2012;118:6260-9.

13. Braeken AP, Kempen GI, Eekers D, et al. The usefulness and feasibility of a screening instrument to identify psychosocial problems in patients receiving curative radiotherapy: a process evaluation. BMC Cancer 2011;11:479.

14. Lavergne C, Taylor A, Gillies C, et al. Understanding and addressing the informational needs of radiation therapists concerning the management of anxiety and depression in patients receiving radiation therapy treatment. J Med Imaging Radiat Sci 2015;46:30-6.

15. Kissane DW, Bylund CL, Banerjee SC, et al. Communication skills training for oncology professionals. J Clin Oncol 2012;30:1242-7.

16. Uitterhoeve RJ, Bensing JM, Grol RP, et al. The effect of communication skills training on patient outcomes in cancer care: a systematic review of the literature. Eur J Cancer Care 2010;19:442-57.

17. Moore PM, Rivera Mercado S, Grez Artigues M, et al. Communication skills training for healthcare professionals working with people who have cancer. Cochrane Database Syst Rev 2013;3:CD003751.

18. Pace R, Pluye P, Bartlett $G$, et al. Testing the reliability and efficiency of the pilot Mixed Methods Appraisal Tool (MMAT) for systematic mixed studies review. Int J Nurs Stud 2012;49:47-53.

19. Moher D, Liberati A, Tetzlaff J, et al. Preferred reporting items for systematic reviews and meta-analyses: the PRISMA statement. PLoS Med 2009;6:e1000097.

20. Halkett GK, Schofield P, O'Connor M, et al. Development and pilot testing of a radiation therapist-led educational intervention for breast cancer patients prior to commencing radiotherapy. Asia Pac J Clin Oncol 2012;8:e1-8.

21. Halkett GK, O'Connor M, Aranda S, et al. Pilot randomised controlled trial of a radiation therapist-led educational intervention for breast cancer patients prior to commencing radiotherapy. Support Care Cancer 2013;21:1725-33.

22. Butlin H, Salter KL, Williams A, et al. PracticeCALM: coaching anxiety lessening methods for radiation therapists: a pilot study of a skillsbased training program in radiation oncology. J Med Imaging Radiat Sci 2016;47:147-54.

23. Gibon AS, Merckaert I, Liénard A, et al. Is it possible to improve radiotherapy team members' communication skills? A randomized study assessing the efficacy of a 38-h communication skills training program. Radiother Oncol 2013;109:170-7.

24. Merckaert I, Delevallez F, Gibon AS, et al. Transfer of communication skills to the workplace: impact of a 38-hour communication skills training program designed for radiotherapy teams. J Clin Oncol 2015;33:901-9.

25. Liénard A, Delevallez F, Razavi D, et al. Is it possible to improve communication around radiotherapy delivery: a randomized study to assess the efficacy of team training? Radiother Oncol 2016;119:361-7.

26. Halkett $\mathrm{G}, \mathrm{O}^{\prime}$ Connor M, Aranda S, et al. Communication skills training for radiation therapists: preparing patients for radiation therapy. J Med Radiat Sci 2016;63:232-41.

27. Hollingworth W, Metcalfe C, Mancero S, et al. Are needs assessments cost effective in reducing distress among patients with cancer? A randomized controlled trial using the distress thermometer and problem list. J Clin Oncol 2013;31:3631-8.

28. Timmermans LM, van der Maazen RW, van Spaendonck KP, et al. Enhancing patient participation by training radiation oncologists. Patient Educ Couns 2006;63:55-63.

29. Pendleton D, Schofield T, Tate P, et al. The new consultation: developing doctor-patient communication. 2003.

30. Zigmond AS, Snaith RP. The hospital anxiety and depression scale. Acta Psychiatr Scand 1983;67:361-70.

31. Roter D, Larson S. The Roter interaction analysis system (RIAS): utility and flexibility for analysis of medical interactions. Patient Educ Couns 2002;46:243-51.

32. Baker F, Denniston M, Zabora J, et al. A POMS short form for cancer patients: psychometric and structural evaluation. Psychooncology 2002;11:273-81.

33. Cohen S, Kamarck T, Mermelstein R. Perceived stress scale measuring stress: a guide for health and social scientists. 1994:235-83.

34. Halkett GKB, Merchant S, Jiwa M, et al. Effective communication and information provision in radiotherapy - the role of radiation therapists. J Radiother Pract 2010;9:3-16.

35. Martin K-L, Hodgson D. The role of counselling and communication skills: how can they enhance a patient's 'first day' experience? J Radiother Pract 2006;5:157-64.

36. Dong S, Butow PN, Costa DS, et al. The influence of patientcentered communication during radiotherapy education sessions on post-consultation patient outcomes. Patient Educ Couns 2014;95:305-12.

37. Maamoun J, Fitch M, Barker R, et al. Results of a radiation therapist opinion survey identifying, measuring and addressing radiation 
therapy patient supportive care needs. J Med Imaging Radiat Sci 2009;40:24-31.

38. Burns PB, Rohrich RJ, Chung KC. The levels of evidence and their role in evidence-based medicine. Plast Reconstr Surg 2011;128:305-10.

39. Michie S, van Stralen MM, West R. The behaviour change wheel: a new method for characterising and designing behaviour change interventions. Implement Sci 2011;6:42.

40. Hulley L, Cashell A, Feuz C, et al. Communicating with emotional patients: thoughts, skills, and influencing factors for ontario radiation therapists. J Med Imaging Radiat Sci 2016;47:315-22.
41. Halkett GKB, McKay J, Shaw T. Improving students' confidence levels in communicating with patients and introducing students to the importance of history taking. Radiography 2011;17:55-60.

42. Heaven C, Clegg J, Maguire P. Transfer of communication skills training from workshop to workplace: the impact of clinical supervision. Patient Educ Couns 2006;60:313-25.

43. Halkett G, O'Connor M, Jefford M, et al. RT Prepare: a radiation therapist-delivered intervention reduces psychological distress in women with breast cancer referred for radiotherapy. $\mathrm{Br} J$ Cancer 2018;118:1549-58. 